\title{
Indolent Neutrophil Response to Endotoxin in Newborn Rats
}

\author{
KENNETH E. SCHUIT ${ }^{(22)}$ AND RICHARD E. KREBS, JR. \\ Department of Pediatrics, University of Pittsburgh School of Medicine and Children's Hospital of Pittsburgh. \\ Pittsburgh Pennsylvania, USA
}

\begin{abstract}
Summary
The blood neutrophil response to endotoxin challenge was determined in one-day-old and young adult rats to test the hypothesis that the neonate is unable to mobilize neutrophils from bone marrow to the peripheral circulation at a rate similar to adults. Adult animals responded to endotoxin with a brief neutropenia followed rapidly by marked neutrophilia. The maximum adult neutrophil count occurred at $11 \mathrm{hr}$ after challenge and returned to baseline values by $28 \mathrm{hr}$. In contrast, one-day-old rats showed a prolonged neutropenia after a comparable injection. Peak neutrophil counts in neonates occurred later than those seen in adults (16 versus $11 \mathrm{hr}$ ) and were also lower. However, neutrophilia, once established in the neonates, persisted considerably longer than in adults.

The age at which the adult response to endotoxin is achieved was assessed by bleeding animals of increasing ages $7 \mathrm{hr}$ after endotoxin challenge. A gradual progression toward the adult neutrophil response began at 2 wk of age. The most rapid change in endotoxin responsiveness occurred after 6 wk of age.
\end{abstract}

\section{Speculation}

The neonate, although probably possessing adequate bone marrow neutrophil reserves, may be unable to mobilize these stores rapidly and effectively. Coupled with other recognized defects in host defenses, this indolent response to inflammatory stimuli may in part be responsible for the unique propensity of the neonate to serious infection.

An increase in the number of circulating blood neutrophils is a common response to inflammatory stimuli and represents an important factor in host defenses against infection. This neutrophilia is due to the accelerated release of mature cells from the bone marrow and to the demargination of neutrophils from vessel walls (3). Release of neutrophils into the peripheral circulation in response to agents such as endotoxin, $(2,3,5)$, etiocholanolone $(6$, $20)$, and corticosteroids ( 8 ) has been studied extensively in adults; however, little is known concerning the neonate's response to these stimuli. Furthermore, previous studies of leukocyte responses to infection in human neonates have been concerned with the peripheral leukocyte count at the time of diagnosis, but have not considered the kinetics of white blood cell production and mobilization $(11,15)$.

We have recently demonstrated indolent recruitment of neutrophils in neonatal rats after focal infection with group B streptococci (16). Such a response could be explained by defects in any of several systems including lack of serum chemotactic factors, abnormal leukocyte chemotaxis, or inefficient bone marrow release.

To test the hypothesis that the neonate is unable to mobilize neutrophils from bone marrow to the peripheral circulation at a rate similar to adults, we have assessed the neutrophil response of newborn rats to endotoxin, an agent which releases neutrophils from bone marrow reserves.

\section{MATERIALS AND METHODS}

Rats of the Sprague-Dawley strain ranging in age from one day through $8 \mathrm{wk}$ were given injections intraperitoneally with $1 \mu \mathrm{g} / \mathrm{g}$ of body weight of lipopolysaccharide (Sigma Chemical Co., St. Louis, MO., phenol-extracted from Salmonella aborti equi). Animals were also given sham-injections with saline. Up to $36 \mathrm{hr}$ after challenge, blood was collected at specific intervals by decapitation of the neonates and from cardiac puncture or from the tail vessels of adults. In all cases, only freely flowing blood was sampled. (No significant differences could be detected in the total leukocyte count or differential in blood drawn by cardiac puncture or from the tail.) Blood smears were Wright-stained, and the cell types were enumerated, identifying 100 cells or the total number found on a slide. The total leukocyte count was determined with a $3 \mu \mathrm{l}$ sample, using an electronic counter (Coulter counter, Hialeah, FL). In all cases, nucleated red blood cells accounted for less than $0.5 \%$ of the total erythrocytes. Ten different experiments were performed with an average of twelve determinations for each time interval. The results of these neutrophil counts are presented as means \pm the standard deviation.

\section{RESULTS}

Figure 1 shows the neonatal and adult responses to endotoxin. Adult animals responded to intraperitoneal injection of endotoxin with a brief neutropenia followed rapidly by marked neutrophilia. The maximum adult neutrophil count $\left(18.8 \times 10^{3}\right.$ cells $\left./ \mathrm{mm}^{3}\right)$ occurred at $11 \mathrm{hr}$ then decreased, and returned to prechallenge values by $28 \mathrm{hr}$ (Fig. 1). In contrast, one-day-old rats showed a prolonged neutropenia after a comparable injection of endotoxin; the neutrophil count did not approach prechallenge values for 9 hr. At $11 \mathrm{hr}$ after challenge, when the adult neutrophilia was at its peak, the neonates had an average value of only $6.45 \times 10^{3}$ neutrophils per $\mathrm{mm}^{3}(P<0.001)$. Peak neutrophil counts in neonates occurred later than those seen in adults ( 16 versus $11 \mathrm{hr}$ ) and were also lower $\left(13.8 \times 10^{3}\right.$ versus $\left.18.9 \times 10^{3} ; P<0.001\right)$. However, neutrophilia in the neonates persisted considerably longer than in adults, remaining in the range of $12 \times 10^{3} / \mathrm{mm}^{3}$ at $36 \mathrm{hr}$. Rats given injections of saline rather than endotoxin did not show changes in their neutrophil values, suggesting that the changes seen in Figure 1 were not due to stress.

In an attempt to quantitate both the magnitude and duration of neutrophil responses in adults and neonates, the areas under the two curves shown in Figure 1 were measured. The area under the curve generated by plotting the adult neutrophil response was 1.76 $\times 10^{6}$ cell $\mathrm{hr}$, whereas that under the neonatal curve was $2.22 \times$ $10^{6}$ cell hr.

To determine the age at which the adult response to endotoxin was achieved, animals from one day to $8 \mathrm{wk}$ in age were given injections of $1 \mu \mathrm{g}$ of endotoxin per $\mathrm{g}$ of body weight. All animals 


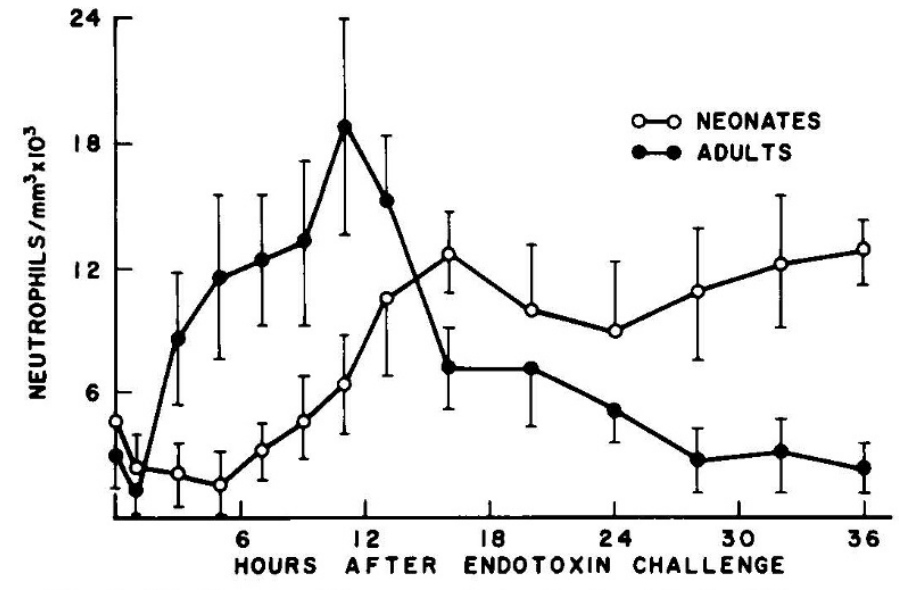

Fig. 1. Blood neutrophil response to $1 \mu \mathrm{g} / \mathrm{g}$ of endotoxin. Points, mean \pm S.D. of an average of 12 animals.

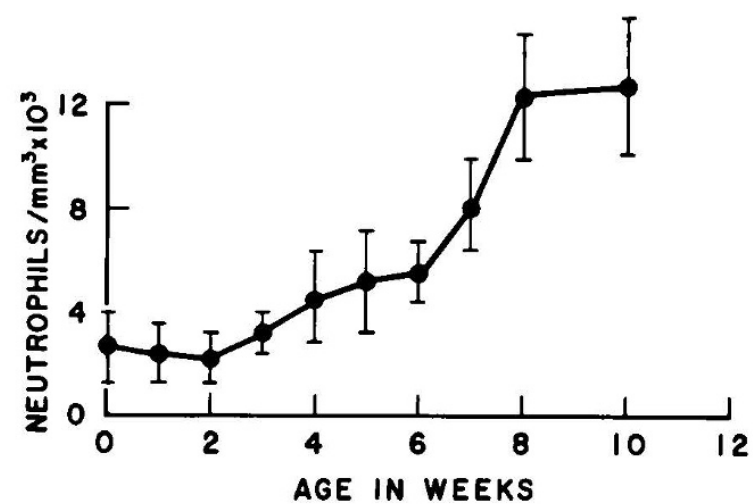

Fig. 2. Age-related response to endotoxin. Rats of different ages were given injections intraperitoneally of endotoxin and bled $7 \mathrm{hr}$ later. Mean \pm S.D.

were bled $7 \mathrm{hr}$ after challenge, an interval in which adults (but not neonates) show a three-fold increase over baseline values in circulating neutrophils. Figure 2 shows a gradual progression toward the adult neutrophil values that begins at 2 wk of age. At $6 \mathrm{wk}$, the 7-hr response was nearly twice that of the one-day-old pups, but was still less than that measured in adult animals. The most rapid change in endotoxin responsiveness occurred after 6 wk of age.

\section{DISCUSSION}

Endotoxin can cause both neutropenia, by accelerating neutrophil outflow from the blood, and neutrophilia, brought about by the release of mature cells from the bone marrow (3). Although these two phenomena are dose related (3), the overall effect of experimental endotoxin administration is frequently a transient neutropenia followed by neutrophilia $(5,18)$. The experiments reported here suggest that the rate of mobilization and distribution of neutrophils after endotoxin challenge in the neonatal rat is different from that in the adult. Not only was initial neutropenia prolonged in neonates, but the rate of neutrophil recruitment into the circulating pool was more indolent than in adults, and neutrophilia, once initiated in the neonates, persisted many hr after the adult values had returned to baseline values. The overall effect was a similarity in the areas under the two curves, suggesting that the newborn is not deficient in total bone marrow reserves, but is unable to mobilize these stores rapidly and efficiently. Similar conclusions can be drawn from the observations of Squire et al. (19) who have reported neutropenia and normal bone marrow in human neonates dying of sepsis. On the other hand, Christensen and Rothstein (4) have reported reduction of the neutrophil storage pool in human infants dying from sepsis, suggesting that the neutropenia associated with neonatal infections may be due to marrow depletion as well as indolent release of neutrophils.

Inasmuch as a ready supply of neutrophils is important in normal host defenses, the mobility of marrow reserves plays an important role in determining the outcome of serious infection. The mechanisms which regulate the mobilization of marrow neutrophils are incompletely understood, although a humoral "granulocyte-releasing factor" has been demonstrated in both experimental animals (2) and humans (6). The data presented here raise the possibility that this factor, while present in the neonate, may be released and extinguished inefficiently.

Other aspects of phagocyte function in the neonate are also defective. Leukocytes from stressed or ill infants may not function efficiently, as Forman and Stiehm (9) and Wright et al. (21) showed that the cells from clinically abnormal infants showed diminished phagocytosis and killing. Similarly, Anderson (1) has reported depression of hexose monophosphate shunt activity in septic neonates. Finally, chemotaxis by newborn leukocytes is depressed compared to adult cells $(10,14)$.

The propensity of neonates to serious infection is well established (13). This susceptibility may be related to indolent rates of response to microbial invasion. In addition to the slow rate of neutrophil response observed in these experiments, we have already demonstrated a decreased rate of monocyte phagocytosis in human neonates (17) and slow neutrophil and macrophage response to infections in newborn rats (16). Coupled with recognized defects in chemotaxis $(10)$ and opsonin production $(7,9,12)$, an indolent response to infection might render the newborn particularly vulnerable to bacterial infections of low intensity which in the adult might be controlled easily by more efficient host defenses.

\section{REFERENCES AND NOTES}

1. Anderson, D. C., Pickering, L. K., and Feigin, R. D.: Leukocyte function in normal and infected neonates. J. Pediatr., 85: 420 (1974).

2. Boggs, D. R., Chervenick, P. A., Marsh, J. C., Cartwright, G. E., and Wintrobe, M. M.: Neutrophil-releasing activity in plasma of dogs injected with endotoxin. J. Lab. Clin. Med., 72: 177 (1968).

3. Chervenick, P. A., Boggs, D. R., Marsh, J. C., Cartwright, G. E., and Wintrobe, $M$. M.: The blood and bone marrow neutrophil response to graded doses of endotoxin in mice. Proc. Soc. Exp. Biol. Med., 126: 891 (1967).

4. Christensen, R. D., and Rothstein, G.: Exhaustion of mature marrow neutrophils in neonates with sepsis. J. Pediatr., 96: 316 (1980).

5. Dale, D. C., Fauci, A. S., Guerry, D., and Wolf, S. M.: Comparison of agents producing a neutrophilic leukocytosis in man. J. Clin. Invest., 56: 808 (1975).

6. Dale, D. C., Guerry, D., and Wolf, S.: Neutrophil-releasing activity in plasma of normal human subjects injected with etiocholanolone. Proc. Soc. Exp. Biol. Med., 156: 192 (1977).

7. Dossett, J. H., Williams, R. C., and Quie, P. G.: Studies on interaction of bacteria, serum factors and polymorphonuclear leukocytes in mothers and newborns. Pediatrics, 44: 49 (1967).

8. Fauci, A. S., Dale, D. C., and Barlow, J. E.: Glucocorticosteroid therapy: mechanisms of action and clinical considerations. Ann. Intern. Med., 84: 304 (1976).

9. Forman, M. L., and Stiehm, E. R.: Impaired opsonic activity but normal phagocytosis in low-birth weight infants. N. Engl. J. Med., 281: 926 (1969).

10. Klein, R. B., Fischer, T. J., Gard, S. E., Biberstein, M., Rich, K. C., and Stiehm, E. R.: Decreased mononuclear and polymorphonuclear chemotaxis in human newborns, infants and young children. Pediatrics, 60: 467 (1977).

11. Manroe, B. L., Weinberg, A. G., Rosenfeld, C. R., and Browne, R.: The neonatal blood count in health and disease. J. Pediatr., 95: 89 (1979).

12. McCracken, G. H., and Eichenwald, H. F.: Leukocyte function and the development of opsonic and complement activity in the neonate. Am. J. Dis. Child., I21: 120 (1971).

13. Naeye, R. L.: Causes of perinatal mortality in the U. S. J. Am. Med. Assoc., 238: 228 (1977).

14. Pahwa, S. G., Pahwa, R., Grimes, E., and Smithwick, E.: Cellular and humora components of monocyte and neutrophil chemotaxis in cord blood. Pediatr. Res., 11: 677 (1977)

15. Pursky, A., Palko, J., Milner, R., and Akenzua, M. B.: The hematology of bacterial infections in premature infants. Pediatrics, 57: 839 (1976).

16. Schuit, K. E., and DeBiasio, R.: Cellular responses to neonatal Group B streptococcal infection. Nineteenth Interscience Conference on Antimicrobial Agents and Chemotherapy, Boston (1979).

17. Schuit, K. E., and Powell, D. A.: Phagocytic dysfunction in monocytes of normal newborn infants. Pediatrics, 65: 501 (1980). 
18. Smith, W. W., Alderman. M. D., and Cornfield, J.: Granulocyte release by endotoxin in normal and irradiated mice. Am. J. Physiol., 201: 396 (1961).

19. Squire, E., Favara, B., and Todd, J.: Diagnosis of neonatal bacterial infection hematologic and pathologic findings in fatal and nonfatal cases. Pediatrics, 64 : 60 (1979).

20. Wolff, S. M., Kimball, H. R., Perry, S., Root, R., and Kappas, A.: The biological properties of etiocholanolone. Ann. Intern. Med., 67: 1268 (1967).
21. Wright, W. C.. Anke, B. J., Herbert, J., and Stiehm, R.: Decreased bactericidal activity of leukocytes of stressed newborn infants. Pediatrics, 56: 579 (1975).

22. Requests for reprints should be addressed to: Dr. Kenneth E. Schuit. Department of Pediatrics, Children's Hospital of Pittsburgh, 125 DeSoto St., Pittsburgh. PA 15213 (USA).

23. Received for publication February 7,1980

24. Accepted for publication May 13, 1980

Copyright (C) 198 I International Pediatric Research Foundation, Inc. $0031-3998 / 81 / 1501-0047 \$ 02.00 / 0$ 